\title{
Common bile duct stones, an experience in Ondokuz Mayis University
}

\author{
Kağan Karabulut, Gökhan Selçuk Özbalcı, Erol Kılıç, Tuğrul Kesicioğlu, Gökhan Lap, İsmail Alper Tarım, \\ Hamza Çınar, Ayfer Kamalı Polat, Bahadır Bülent Güngör, Kenan Erzurumlu*
}

Department of General Surgery, Faculty of Medicine, Ondokuz Mayis University

\section{ARTICLE INFO}

\section{Article History}

Received $\quad 06 / 02 / 2013$

Accepted $\quad 25 / 02 / 2013$

\section{* Correspondence to:}

Kenan Erzurumlu

Department of General Surgery,

Faculty of Medicine,

Ondokuz Mayis University,

Kurupelit, Samsun, Turkey

e-mail: kerzurum@omu.edu.tr

\section{Keywords:}

Common bile duct stones

Choledocholithiasis

Choledochoduodenostomy

Transduodenal sphincteroplasty

Surgery

\author{
ABSTRACT
}

Common bile duct stones, obstructive jaundice, cholangitis and acute pancreatitis are diseases that can lead to serious complications. In our clinic between May 1993 and October 2011 the results of 101 patients who underwent surgery for common bile duct stone were retrospectively evaluated. Among 101 patients who were included in the study, 45 had symptomatic gallstones accompanied by common bile duct stone, 27 had mechanical icterus, 15 had common bile duct stone and 8 had cholangitis (five patients with suppurative cholangitis), six had acute cholecystitis. Thirthy one patients with common bile duct stones were treated with endoscopic retrograde cholangiopancreatography (ERCP). Surgical procedures were as follows; choledochoduodenostomy in 50 cases, T-tube drainage in 17 patients and transduodenal sphincteroplasty in three patients. Synchronous cholecystectomies were performed in all patients who had not undergone biliary surgery before. Early postoperative mortality was $3.9 \%$. In this study, we detected choledocholithiasis in $11.31 \%$ of the all symptomatic cholelithiasis cases. Since our clinic provide tertiary healthcare, this rate becomes $9.85 \%$ by excluding those who underwent cholecystectomy for common bile duct stones at other hospitals. Given that the patients who referred to our clinic are in high-risk group, the actual rate of choledocholithiasis in our society is expected to be slightly below that value.

J. Exp. Clin. Med., 2013; 30:109-114

\section{Introduction}

Cholelithiasis is the most common biliary disease, and choledocholithiasis is one of its serious complications (VázquezSequeiros et al., 2011). The incidence of choledocholithiasis ranges from $3 \%$ to $10 \%$ in patients with gallstones undergoing laparoscopic cholecystectomy for symptomatic cholelithiasis and rises gradually with age, and is as high as $31 \%$ between 61 and 70 years and 52\% between 81 and 90 years. Choledochal stones have clinical importance due to potentially severe complications as obstructive jaundice, cholangitis and acute pancreatitis (Oría et al.,1991; Freitas et al., 2006; Lee et al., 2008)

The first gallbladder operation was performed by John Stough Bobb in 1867. He made a cholecystotomy, removed the gallstones, and sutured the gallbladder. The first cholecystectomy was done in 1882 by Carl Langenbuch. In 1888, Bernhard Riedel, removed several choledochal stones and carried out a side-to-side anastomosis between the bile duct and duodenum. This was the first choledochoduodenostomy (CD) and was short lived. The patient died 9 hour later. At the autopsy, an anastomotic leakage was found. Succesfull CD for an impacted common duct stone was done by Oskar Sprengel in Germany in 1891(Leppard et al., 2011; Steven et al., 2004).

By the time, biliodigestive anastomosis (BDA) have been commonly used for choledochal diesases both malign and benign diseases. The use of a Roux-en-Y jejunal limb to create a hepaticojejunostomy as commonly used today was first reported by Robert Dahl of Stockholm in 1909 (Steven et al., 2004).

Since the introduction of endoscopic retrograde cholangiopancreatography (ERCP) in the 1970s and of endoscopic sphincterotomy (ES) in 1974, endoscopic techniques for the diagnosis and therapy of biliary and pancreatic disorders have been increased (Vaira et al., 1993).

Endoscopic retrograde cholangiography (ERC) with endoscopic sphincterotomy (ES) and extraction of stone was first described in 1974 and has been a first-line management strategy for choledocholithiasis for the past 2 decades (Demling et al., 1974). 
The diagnosis of common duct stones can be difficult because clinical and biochemical evidence can be subtle or even absent. Several modalities can be used for the diagnosis of choledocholithiasis. These include transabdominal ultrasonography (US), computed tomography (CT), microscopic examination of duodenal bile, magnetic resonance cholangiopancreatography (MRCP), ERCP, intraoperative cholangiography, endoscopic ultrasonography, (EUS) and percutaneous transhepatic cholangiography (PTC) (Sgouros et al., 2006).

Although the results of diagnostic and surgical methods have been well documented, choledochal stones still remain controversial in surgery with a range of therapeutic options and potentially severe complications. In this study, the results of our cases of choledochal stones treated by an algorithm were prospectively presented (Fig. 1).

\section{Materials and methods}

The records of the 893 patients who referred to Ondokuz Mayıs University, Department of General Surgery with symptomatic gallstones and common bile duct stones between May 1993 and October 2011 were examined retrospectively.

In this study, the ratio of common bile duct in gallstone cases and age-sex relationship were initially investigated. Thereafter, diagnosis, treatment strategies, outcomes, morbidity and mortality rates of the patients with common bile duct stone were evaluated. The patients were contacted via phone numbers and their latest status were investigated.

The significance of the differences between proportions were done by Z-tests for proportions. All statistical analysis were conducted by SPSS statistical package programme version 18, the significance level $\alpha=0.05$ was used for all tests. The results of our cases of choledochal stones treated by an algorithm were prospectively presented (Figure 1).

\section{Patient selection}

The patients having pathologies such as common bile duct stone, cholangitis, hydatid cyst opened in the biliary tract (one case), gallbladder cancer (one case) and pancreatic cancer (one case) were included in the study and those without common bile duct stone were excluded.

\section{Treatment}

The patients who referred to our clinic were treated according to algorithm in Figure 1. While all the patients who referred to our department after 2001 with suspected or common bile duct stone were routinely undergoing ERCP, those who referred before 2001 and those with failed ERCP underwent surgery. The patients who have not had cholecystectomy underwent synchronous cholecystectomy.

ERCP: Papilla was reached by the use of side-viewing duedonoscope in routinely prepared patients. A $\sim 1.5 \mathrm{~cm}$ incision was made using a sphincterotome. Stone-debris and other factors causing obstruction were removed by entering choleduct with basket or Fogarty catheter.

Choledochoduodenostomy (CD): CD was performed with Floercken and Mallet-Guy absorbable materials by us-

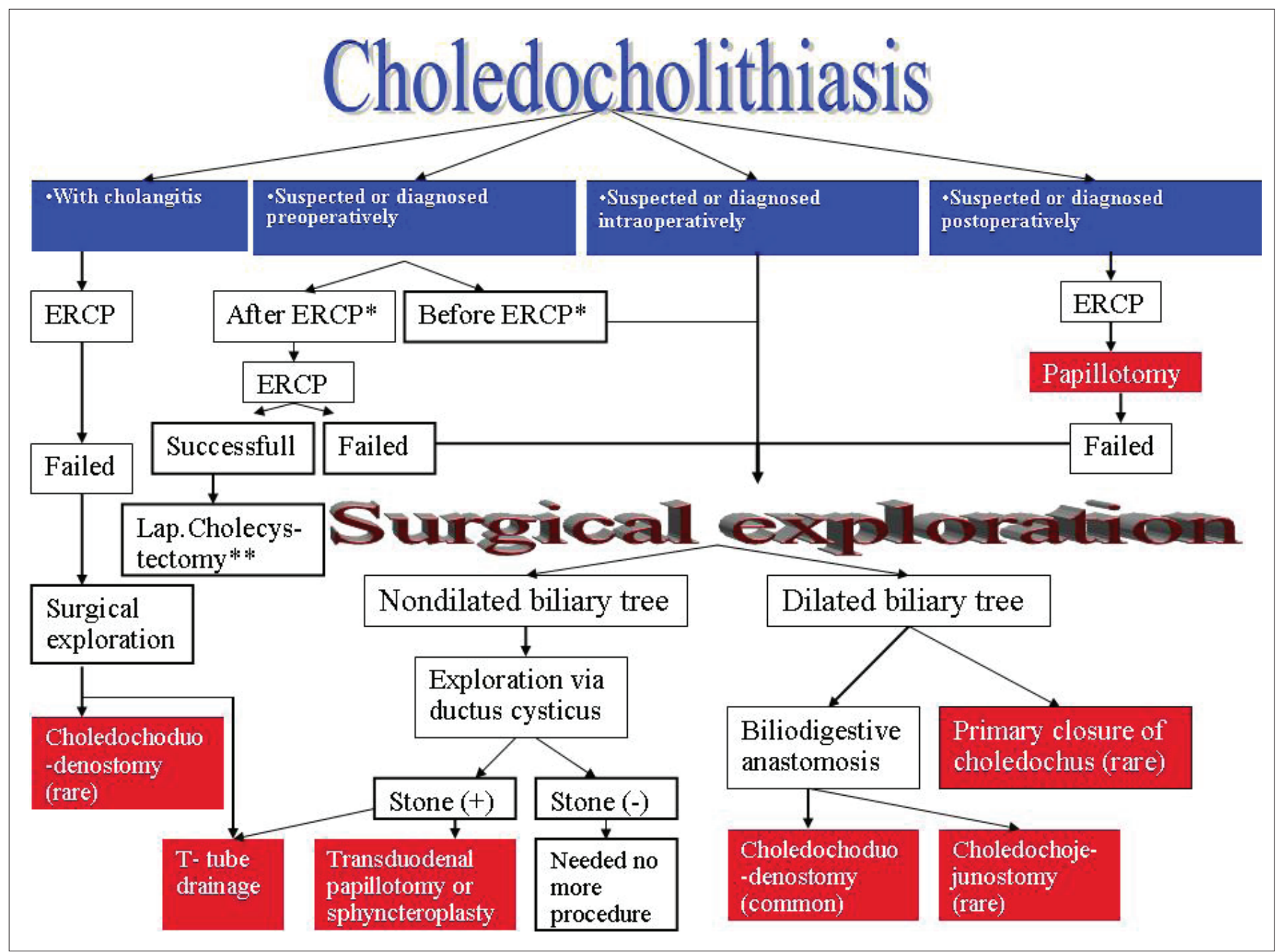

Fig. 1. Algorithm of choledochal stones treatment 
ing a single-layer suture in patients with common bile duct diameter greater than $1.5 \mathrm{~cm}$.

T-tube drainage: Was performed in patients with narrow common bile duct prior to ERCP or in cases where ERCP failed as well as in cholangitis and suppurative cholangitis cases.

Transdoudenal sphincteroplasty (TDS): It was preferred in choledocholithiasis cases where common bile duct was in normal calibration. Intraoperative cholangiography was performed by a transcystic catheter. Then the catheter was advanced passing through the sphincter of Oddi. After performing duodenotomy, papilla was detected by the catheter located inside the lumen. The sphincter was resected by a $2 \mathrm{~cm}$ incision at 10-11 o'clock position (Sphincteroplasty). Sutures were placed to the both edges of the incision. Common bile duct was cleared using pliers and fogarty catheter inserted through the papilla. Catheter was removed at the end of the process. Ductus cysticus remnant was ligated and duodenotomy line was sutured.

\section{Results}

The study was conducted with 893 patients with suspected or diagnosed common bile duct stones and symptomatic gallstones. All the patients were evaluated for choledochal stones. Of the 893 patients, $607(67.97 \%)$ were female and $286(32.03 \%)$ were male. The mean age of the patients was $51.16 \pm 14.456$. Three hundred and thirty-seven patients (37.14\%) were over 60 years of age. Of 101 patients who, were included in the study, 45 had symptomatic gallstones accompanied by common bile duct stone, 27 had mechanical icterus, 15 had common bile duct stone and 8 had cholangitis (5 patients with suppurative cholangitis), 6 had acute cholecystitis

While the rate of biliary duct stone accompanied by symptomatic gallstones was $11.31 \%$, the incidence of common bile duct stone was $9.85 \%$ in patients who had not undergone billiary surgery before. Gall stones / cholelithiasis rate was $13.64 \%$ in men and was $10.21 \%$ in women $(p=0.151)$. The same ratio was $18.93 \%$ and $6.83 \%$ in patients over 60 and under 60 years of age respectively $(\mathrm{p}<0.001)$. ERCPs were performed in 44 patients with suspected or diagnosed common bile duct stones preoperatively. ERCPs were failed in $13(29.55 \%)$ cases and this group of patients underwent surgery for common bile duct stones. Thirty one patients with common bile duct stones were treated with ERCP.

ERCPs were performed postoperatively in only 5 patients on suspicion of common bile duct stones in the patients on whom ERCPs were performed successfully. Laparoscopic cholecystectomies were performed in group of patients on whom ERCPs were performed successfully.

Seventy patients with failed or inadequate ERCP underwent surgery for common bile duct stones. Surgical procedures were as follows; CD in 50 cases (49 Floercken, 1Mal-

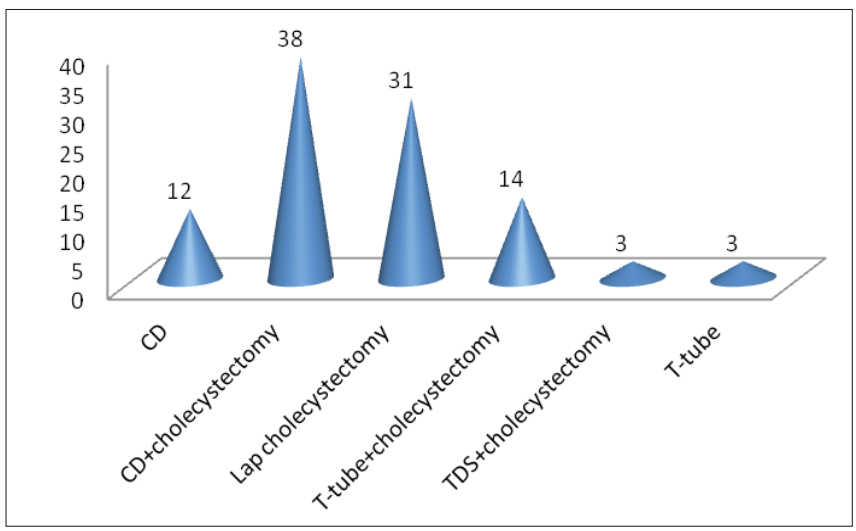

Fig. 2. Surgical treatment

let-Guy), T-tube drainage in 17 patients and transduodenal sphincteroplasty in three patients. Synchronous cholecystectomies were performed in all patients who had not undergone biliary surgery before (Fig. 2).

Thirteen patients with choledocholithiasis have already undergone (1 month-20 years) biliary intervention.

Of these, 10 had only cholecystectomy. In addition to cholecystectomy, common bile duct exploration was used in three patients, one of whom had common bile duct exploration and T-tube drainage at another hospital a month ago. However, open surgical intervention was preferred due to the biliary fistula caused by overlooked stones and failed ERCP. Again, one patient underwent open surgical intervention (CD + basket and extraction of stones) because of the bile tract obstruction caused by the basket used in ERCP for common bile stones which were detected 17 years after cholecystectomy. A sixty-year-old patient had cholecystectomy 20 years ago and common bile duct exploration 12 years ago. Twelve patients were treated with choledochoduodenostomy whereas one was treated with TDS. In patients who were surgically intervened (30 patients), surgical intervention for the common bile duct was done in non-ERCP period, 50 patients underwent surgery for common bile duct stones in ERCP-performed period. Of the 50 patients, ERCP failed in 37 and those with failed ERCP underwent surgery for common bile duct stones.

\section{Morbidity}

Choledochoduodenostomy group: 4 patients (8\%) developed surgical wound infection and $2(4 \%)$ biliary fistula. Five of the six patients recovered with conservative treatment. The infection was treated with secondary suture in one patient who developed evisceration (14\%). Pre- and post-operative ERCP+Laparoscopy cholecystectomy group: Two patients had pancreatic abscess and portside infection+hepatic abscess $(6.45 \%)$.

Cholecystectomy + Transduodenal sphincteroplasty group: One patient developed wound infection (33.33\%). No complication was developed in cholecystectomy + T-tube drainage group (Table 1).

\begin{tabular}{|c|c|c|c|c|c|}
\hline & Wound site infection & Biliary fistula & Evisceration & Pancreatic abscess & Liver abscess \\
\hline Choledochoduodenostomy & $4(8 \%)$ & $2(4 \%)$ & $1(2 \%)$ & - & - \\
\hline Laparoscopy cholecystectomy & $1(3 \%)$ & - & - & $1(3 \%)$ & $1(3 \%)$ \\
\hline Transdoudenal sphincteroplasty & $1(33 \%)$ & - & - & - & - \\
\hline T-tube drainage & - & - & - & - & - \\
\hline Total & $6(5.9 \%)$ & $2(1.9 \%)$ & $1(0.9 \%)$ & $1(0.9 \%)$ & $1(0.9 \%)$ \\
\hline
\end{tabular}


Table 2. Mortality

\begin{tabular}{lcccc} 
Age/gender & Diagnosis & Operation & Day of death & Cause of death \\
\hline $\mathbf{8 2} / \mathbf{M}$ & choledocholithiasis & CD + splenectomy + cholecystectomy & 5. day & cardiopulmonary insufficiency \\
$\mathbf{4 6 / M}$ & suppurative cholangitis & T-tube drainage & Septic shock \\
$\mathbf{7 7 / M}$ & suppurative cholangitis +liver abscees & T-tube drainage + cholecystectomy & 27. day & Multi organ failure \\
$\mathbf{7 6 / F}$ & choledocholithiasis & CD + cholecystectomy & 2. day & cardiopulmonary failure \\
\hline
\end{tabular}

\section{Mortality}

A total of four patients died in the early postoperative period (one month) because of septic shock due to suppurative cholangitis and multi organ failure (two cases). Two patients in choledochoduodenostomy group died because of cardiopulmonary insufficiency. Early postoperative mortality was $3.9 \%$ (Table 2).

\section{The characteristics of the patients who died in the late postoperative period}

They were detected in late period controls and 7 patients died between 2.5 months and 7 years after surgery. Causes of death in two patients were choledocholithiasis, gall bladder and pancreas cancer. Other patients died because of nonbiliary diseases.

\section{Discussion}

Common bile duct stones (CBDS) are present in 6-20\% of patients with cholelithiasis. The incidence of synchronous common bile duct stones and cholelithiasis increases in older patients or/and in the patients with large common bile duct. In this study, we detected choledocholithiasis in $11.31 \%$ of the all symptomatic cholelithiasis cases. Since our clinic provide tertiary healthcare, this rate becomes $9.85 \%$ by excluding those who underwent cholecystectomy for common bile duct stones at other hospitals. Given that the patients who referred to our clinic are in high-risk group, the actual rate of choledocholithiasis in our society is expected to be slightly below that value.

The basic principles of common bile duct stone treatment are as follows; extraction of the stones and ensuring bile flow, provision of a large lumen for missed / subsequently occurring stones and prevention of bile duct injury and stricture formation. Anatomo-physiological features of biliary system and structural changes caused by common bile duct stones have effects on therapy choice. For this reason, there is no standard method of treatment for common bile duct stones.

Surgical treatment of common bile duct stones acquires a new strategy with the diagnostic and therapeutic applications of ERCP. ERCP was the first treatment modality to used in common bile duct stone management, and exploration and surgical interventions have reduced the need for common bile duct exploration. Current treatment options can be summarized under the following headings; ERCP, choleduct drainage (T-tube, transhepatic or ERCP stenting), bilio-digestive anastomosis and primary closure.

Primary closure of the common bile duct after choledochotomy has not been favored due to the higher risk of complications. Choledochoduodenostomy and choledochojejunostomy represent the most widely used biliary-enteric anastomosis.

Anastomosis between hepatic duct / bile duct and jejunum are frequently implemented in bile tract injuries or strictures. Current treatment modalities for bile duct stones are ERCP, choledochoduodenostomy, T-tube drainage and sphincteroplasty.

Exploration of the main bile tract is the first step in choledocholithiasis surgery. It may be performed conventionally or laparoscopically. T-tube drainage has been used in conventional surgery for more than a hundred years.

Laparoscopic common bile duct exploration is difficult to perform and requires much more laparoscopic equipment. It offers a high rate of success ranging from $83 \%$ to $96 \%(93.3$ $\%$ in 2008, Cochrane Review (Martin et al., 2006)). The morbidity rate ranges from 2 to $17 \%$. Its minor complications are nausea, vomiting, diarrhea, fever, and urinary retention. Major complications are wound infection, bile leakage, abscess and subhepatic collections, complications related to T-tube and systemic complications such as pulmonary, cardiac and renal failure. The mortality rate is reported to be $1-5 \%$ compared with the rate of $4 \%$ to $20 \%$ reported for open elective and emergency procedures in patients over 70 years old. It can be achieved by two methods: via transcystic or choledochotomy (Martin et al.,1983; Hacker et al.,1990; Gonzalez et all.,1997; Siegel et al.,1997; Verbesey et al.,2008).

If the surgical team performing laparoscopic common bile exploration is not experienced or it is not possible to perform ERCP, conventional biliary bile duct stone exploration is considered as the gold standard for the removal of the stones (Verbesey et al., 2008).

After 1980's, the most direct method of dealing with choledocholithiasis (CHL) preoperatively has been the ERCP. Decompression of the ductal system can be achieved by means of endoscopic removal of stones with or without sphincterotomy. The mortality, morbidity and success rates of the procedure have been reported to be ranging from $5 \%$ to $19 \%, 0 \%$ to $2.3 \%$ and $70 \%$ to $90 \%$ respectively (Petelin et al., 2004 ).

Results of the treatment of common bile duct stone with either laparoscopic surgery or with the combined endoscopic sphincterotomy plus laparoscopic cholecystectomy are comparable when performed by well-trained practitioners (Payen et al., 2011). Laparoscopic cholecystectomy can be carried out in early or late period after ERCP. The characteristics and endoscopic procedures of two groups were similar. There were no differences between two groups in terms of operative duration, incidence of surgical complications, restoration of bowel motion, postoperative hospital stay and Laparoscopic cholecystectomy (LC)-related cost. However, total hospital cost of early LC was less than that of delayed LC (Zang et al., 2011).

Because the published morbidity rates for ERCP and laparoscopic common bile duct exploration are roughly equivalent, ERCP with or without sphincterotomy is a good starting point in patients in whom stones are known to be present or strongly suspected, and a laparoscopic cholecystectomy is planned. A recently published Cochrane meta-analysis concluded that in last years, when open cholecystectomies were 
common, open common bile duct exploration was superior to ERCP. In the laparoscopic era, however, laparoscopic exploration and ERCP have very similar success and morbidity rates associated with common bile duct clearance (Martin et al., 2006).

On the other hand, ERCP is not "harmful rosary". Perforations of biliary or intestinal tract, bleeding, pancreatitis, cholangitis, sepsis, insufficient biliary drainage, endoscopic basket impaction are the most common complications of ERCP. In the cases of CHL with no cholelithiasis, after ERCP+sphincterotomy, cholecystitis can be seen about $75 \%$ of patients within few months.

Transduodenal sphincterotomy (TDS) is contraindicated in the presence of a large CBD $(>2 \mathrm{~cm})$ or where there is a long suprasphincteric stricture. Also it should not be applied in the cases of duodenal diverticulum and periampullary inflammation. In the operation, the duodenum is mobilized by using Kocher's maneuver and palpated to localize the stone. If the stone cannot be felt, a Fogarty or feeding catheter or special probe can be placed through the choledochotomy or cystic duct, and passed down toward the duodenum as a landmark for the sphincter. A sphincterotomy (1-2 cm length) is performed at the 10 o'clock position, which should be directly opposite the most common position for the pancreatic duct. Partially resection of sphincter is done and the edge of incision is sutured. Morbidity and mortality rates are similar to endoscopic sphincterotomy. Duodenal or biliary fistulas are rarely seen (Hutter et al., 2004; Blumgart, 2007; Majeed et al., 2007).

Patient's age, co-morbid conditions, nutritional status, pre-operative serum bilirubin associated with chronic liver disease, nature and extent of the primary disease and type of anastomosis have been reported to influence the outcomes of biliary-enteric anastomosis BEA (Blankensteijn et al., 1990; Pottakkat et al., 2010).

Post-operative complications of choledochoduodenostomy (CD) including anastomotic leak, hemorrhage, wound infection and cholangitis have also been reported.

The primary outcomes of early complications were divided into groups as local (wound infection, hepatic or intra-abdominal abscess, biloma formation, biliary leak, cholangitis or persistent jaundice, delayed gastric emptying, pancreatic fistula, hemorrhage, pancreatitis, sump syndrome and stricture formation) and systemic complications (chest infection, urinary tract infection, venous thromboembolism, pulmonary edema, acute myocardial infarction, renal failure and systemic sepsis) (Parrilla et al.,1991; Tocchi et al.,2001; Sicklick et al., 2005; Zafar et al., 2011).

Morbidity rate of CD ranged from $3 \%$ to $49 \%$ in the previous reports. Most frequent complications were wound infection (23\%) and bile leakage (up to $13 \%$ ). (Blankensteijn et al.,1990; Chapman et al.,1995; Tocchi et al.,2001; Laasch et al.,2002; Sicklick et al.,2005; Zafar et al.,2011).

The sump syndrome is a rare and late complication of choledochoduodenostomy. The feared sump syndrome is theorized to occur from bile stasis and reflux of duodenal contents into the terminal common bile duct with bacterial overgrowth resulting in cholangitis or hepatic abscess (Leppard et al., 2011).

The prevalence of sump syndrome was reported between $0 \%$ and $9.6 \%$ in prior studies (Madden et al., 1970; De Almeida et al., 1984; Baker et al., 1987; Leppard et al., 2011).

In most cases of sump syndrome, the obstruction is caused by food debris or biliary or both. Caroli-Bosc has determined two factors that could explain the low frequency of this complication. First, a sump with a large anastomosis results in efficient and consistent clearance of food debris that enters the bile duct. Second, although the upstream (hepatic) aspect of the duodenal anastomosis is frequently found to be widely patent, the downstream (sump) aspect is usually narrow and thus prevents the entry and impaction of food debris in the sump segment in most patients (Caroli-Bosc et al., 2000).

Sump syndrome may be treated endoscopically or by conventional surgery. Food debris and stones can be extracted from the sump through the anastomosis with a Dormia basket (Alberti-Flor et al., 1991; Blair et al 1985; Ranjeev et al.,2000; Caroli-Bosc et al.,2000).

In the recent years, mortality after BEA and $\mathrm{CD}$ for benign biliary structure decreased from $10 \%$ to $1 \%$ (Blankensteijn et al., 1990; Chapman et al., 1995; Tocchi et al., 2001; Laasch et al., 2002; Sicklick et al., 2005).

\section{Conclusion}

Incidence of common bile duct stones increases due to the increase of life time. Widespread practical use of ERCP and having successful results, reduces the need for surgery for bile duct stones according to the period prior to ERCP. However, when ERCP is unsuccessful or can not be done, the common bile duct surgery for the common bile duct stones is still the choice of treatment.

\section{REFERENCES}

Alberti-Flor, J.J., Hernandez, M.E., Ferrer, J.P., 1991. Endoscopic treatment of the sump syndrome without sphincterotomy. Gastrointest. Endosc. 37, 107.

Baker, A., Neoptolemos, J., Leese, T., James, D.C., Fossard, D.P., 1987. Long term follow-up of patients with side to side choledochoduodenostomy and transduodenal sphincteroplasty. Ann. R. Coll. Surg. Engl. 68, 253-257.

Blair, A.J., Leung, J.W.C., Cotton, P.B., 1985. Endoscopic treatement of stomal stenosis after choledochoduodenostomy: Preliminary report. Surgery. 97, 487-489.

Blankensteijn, J.D., Terpstra, O.T., 1990. Early and late results following choledochoduodenostomy and choledochojejunostomy. HPB Surg. 2, 151-158.

Blumgart, L.H., 2007. Stones in the common bile duct-clinical features and open surgical approaches and techniques. Ed. Blumgart LH, Surgery of the liver, biliary tract, and pancreas. 4th edition. Elsevier. P.A., USA. pp. 528-547.

Caroli-Bosc, F.X., Demarquay, J.F., Peten, E.P., Dumas, R., Bourgeon, A., Rampal, P., Delmont, J.P., 2000. Endoscopic management of sump syndrome after choledochoduodenostomy: Retrospective analysis of 30 cases. Gastrointest. Endosc. 51, 180-183.

Chapman, W.C., Halevy, A., Blumgart, L.H., Benjamin, I.S., 1995. Postcholecystectomy bile duct strictures. Management and outcome in 130 patients. Arch. Surg. 130, 597-602.

De Almeida, A., Cruz, A., Aldeia, F., 1984. Side to side choledochodenostomy in the management of cholelithiasis and associated disease: Facts 
and fiction. Am. J. Surg. 147, 253-259.

Demling, L., Koch, H., Classen, M., 1974. Endoscopic papillotomy and removal of gallstones: animal experiments and first clinical results [in German].Dtsch. Med. Wochenschr. 99, 2255-2257.

Freitas, M.L., Bell, R.L., Duffy, A.J., 2006. Choledocholithiasis: Evolving standards for diagnosis and management. World J. Gastroenterol. 12, 3162-3167.

Gonzalez, J.J., Sanz, L., Grana, J.L., Bermejo, G., Navarrete, F., Martinez, E., 1997. Biliary lithiasis in the elderly patient: Morbidity and mortality due to biliary surgery. Hepatogastroenterology. 44, 1565-1568.114.

Hacker, K.A., Schultz, C.C., Helling, T.S., 1990. Choledochotomy for calculous disease in the elderly. Am. J. Surg. 160, 610-612.

Hutter, M.M., Rattner, D.W., 2004. Open common bile duct exploration: When is it indicated? In: Cameron JL, editor. Current surgical therapy. 8th edition. Philadelphia. Elsevier Mosby. pp. 392-399.

Laasch, H.U., Martin, D.F., 2002. Management of benign biliary strictures. Cardiovasc. Intervent. Radiol. 25, 457-466.

Lee, S.H., Hwang, J.H., Yang, K.Y., Lee, K.H., Park, Y.S., Park, J.K., Woo, S.M., Yoo, J.W., Ryu, J.K., Kim, Y.T., Yoon, Y.B., 2008. Does endoscopic sphincterotomy reduce the recurrence rate of cholangitis in patients with cholangitis and suspected of a common bile duct stone not detected by ERCP? Gastrointest Endosc. 67, 51-57.

Leppard, W.M., Shary, T.M., Adams, D.B., Morgan, K.A., 2011. Choledochoduodenostomy: Is It Really So Bad? J Gastrointest Surg. 15, 754757.

Madden, J., Chun, J., Kandalaft, S., Parekh, M., 1970. Choledochoduodenostomy: An unjustly maligned surgical problem. Am. J. Surg. 119, 45-54.

Majeed, A.W., Cameron, I.C., 2007. Cholecystolithiasis and stones in the common bile duct: Which approach, when? Ed. Blumgart LH, Surgery of the liver, biliary tract, and pancreas. Elsevier, 4th edition, PA, USA. pp. 565-572.

Martin, D.J., Vernon, D.R., Toouli, J., 2006. Surgical versus endoscopic treatment of bile duct stones. Cochrane Database Syst Rev. CD003327.

Oría, A., Alvarez, J., Chiappetta, L., Spina, J.C., Hernández, N., Iovaldi, M., Ocampo, C., Paladino, A., 1991. Choledocholithiasis in acute gallstone pancreatitis. Incidence and clinical significance. Arch. Surg. 126, 566-568.

Parrilla, P., Ramirez, P., Sanchez, Bueno, F., Perez, J.M., Candel, M.F., Muelas, M.S., Robles, R., 1991. Long-term results of choledochoduode nostomy in the treatment of choledocholithiasis: Assessment of 225 cases. Brth. J. Surg. 78, 470-472.

Payen, J.L., Muscari, F., Vibert, E., Ernst, O., Pelletier, G., 2011. Biliary lithiasis. Presse Med. 40, 567-580.

Petelin, J.B., Pruett, C.S., 2004. Common bile duct stones. In: Cameron JL, editor. Current surgical therapy. 8th edition. Philadelphia. Elsevier Mosby. pp. 392-399.

Pottakkat, B., Vijayahari, R., Prakash, A., Singh, R.K., Behari, A., Kumar, A., Kapoor, V.K., Saxena, R., 2010. Factors predicting failure following high bilio-enteric anastomosis for post-cholecystectomy benign biliary strictures. J. Gastrointest Surg. 14, 1389-1394.

Ranjeev, P., Goh, K., 2000. Retrieval of an impacted Dormia basket and stone in situ using a novel method. Gastrointest. Endosc. 51, 504-506.

Sgouros, S.N., Bergele, C., 2006. Endoscopic ultrasonography versus other diagnostic modalities in the diagnosis of choledocholithiasis. Dig. Dis. Sci. 51, 2280-2286.

Sicklick, J.K., Camp, M.S., Lillemoe, K.D., Melton, G.B., Yeo, C.J., Campbell, K.A., Talamini, M.A., Pitt, H.A., Coleman, J., Sauter, P.A., Cameron, J.L. 2005. Surgical management of bile duct injuries sustained during laparoscopic cholecystectomy: Perioperative results in 200 patients. Ann Surg. 241, 786-792.

Siegel, J.H., Kasmin, F.E., 1997. Biliary tract diseases in the elderly: Management and outcomes. Gut. 41, 433-435.

Steven, A., Ahrendt, Henry, A., 2004. Pitt. Biliary tract. In Sabiston Textbook of Surgery. Ed. Townsend CM, Beauchamp RD, Evers BM, Mattox KL. Saunders Elsevier Company Philadelphia, pp 1597-1642.

Tocchi, A., Mazzoni, G., Liotta, G., Lepre, L., Cassini, D., Miccini, M., 2001. Late development of bile duct cancer in patients who had biliaryenteric drainage for benign disease: A follow-up study of more than 1,000 patients. Ann Surg. 234, 210-214.

Vaira, D., Cairns, S.R., Miglioli, M., Mulé, P., Menegatti, M., Barbara, L., 1993. Biliary surgery without the surgeon! Dig. Dis. 11, $278-287$.

Vázquez-Sequeiros, E., González-Panizo, Tamargo, F., Boixeda-Miquel, D., Milicua, J.M., 2011. Diagnostic accuracy and therapeutic impact of endoscopic ultrasonography in patients with intermediate suspicion of choledocholithiasis and absence of findings in magnetic resonance cholangiography. Rev. Esp. Enferm. Dig. 103, 464-471.

Verbesey, J.E., Birkett, D.H., 2008 Common Bile Duct Exploration for Choledocholithiasis. Surg. Clin. North Am. 88, $1315-1328$.

Zafar, S.N., Khan, M.R., Raza, R., Khan, M.N., Kasi, M., Rafiq, A., Jamy, O.H., 2011. Early complications after biliary enteric anastomosis for benign diseases: A retrospective analysis. BMC Surg. 25, 11-19.

Zang, J., Zhang, C., Zhou, H., Gao, J., 2011. Early laparoscopic cholecystectomy after endoscopic common bile duct stone extraction: The experience from a developing country. Surg. Laparosc. Endosc. Percutan Tech. 21, 120-122. 